\section{Response to: 'New 2019 SLE EULAR/ACR classification criteria are valid for identifying patients with SLE among patients admitted for pericardial effusion' by Sacre et al}

In their letter, Dr Sacre and colleagues ${ }^{1}$ describe an interesting retrospective study on 129 patients with pericardial effusion, of whom 17 were diagnosed with systemic lupus erythematosus (SLE). The authors arrive at a reassuring sensitivity of 100\% for the new European League Against Rheumatism/American College of Rheumatology (EULAR/ACR) 2019 classification criteria. $^{23}$ However, specificity was clearly lower at $84 \%$, below the specificity of the ACR and the Systemic Lupus International Collaborating Clinics (SLICC) criteria. The latter is a somewhat unexpected result. Based on the experience of the last months, the most common reasons for suboptimal specificity in applying the EULAR/ACR 2019 criteria are incorrect attribution to SLE and reliance on non-specific serological tests. Given the data presented by Dr Sacre and colleagues, ${ }^{1}$ both may also have played a role in misclassifying 2 of 6 patients with other autoimmune disease and 3 of 26 patients with idiopathic pericarditis as having SLE.

In addition to serositis, EULAR/ACR classification criteria items in non-SLE patients were limited to fever, joint involvement and low $\mathrm{C} 4$ in patients with other autoimmune diseases. ${ }^{1}$ By attribution rule, ${ }^{2-4}$ these items should not be counted for SLE if due to another autoimmune disease. Similarly, patients without autoimmune disease had fever and proteinuria besides serositis. Again, these should not be counted if in fact attributed to an infection.

Moreover, 2 of 26 patients without an autoimmune disease were reported to have antibodies against double-stranded DNA (dsDNA). This should depend on an assay with at least $95 \%$ specificity against relevant disease controls, ${ }^{2}{ }^{3}$ usually a Crithidia test or radioimmune assay. Such test would be unlikely to become positive in idiopathic pericarditis. AntidsDNA tests of lower specificity, on the other hand, should not be counted.

While we thank Dr Sacre and colleagues ${ }^{1}$ for their interesting data and while the sensitivity results are reassuring, we would like to remind authors of the importance of following the attribution rule of the EULAR/ACR criteria, that the criteria items should only be counted if there is no more likely alternative explanation. ${ }^{2-4}$ Since this single rule has replaced the exclusion criteria for individual items, not following the attribution rule will inevitably lead to underestimating specificity when the new SLE classification criteria are applied.
Martin Aringer $\odot,{ }^{1}$ Karen Costenbader, ${ }^{2}$ Thomas Dörner $\odot{ }^{3}$

\section{Sindhu R Johnson ${ }^{4}$}

${ }^{1}$ Division of Rheumatology, Department of Medicine III, University Medical Center and Faculty of Medicine Carl Gustav Carus, TU Dresden, Dresden, Germany

${ }^{2}$ Division of Rheumatology and Immunology, Department of Medicine, Brigham and Women's Hospital, Harvard Medical School, Boston, Massachusetts, USA

${ }^{3}$ Department of Rheumatology and Clinical Immunology, Charité -

Universitätsmedizin Berlin, Corporate member of Freie Universität Berlin, HumboldtUniversität zu Berlin, and Berlin Institute of Health, Berlin, Germany

${ }^{4}$ Division of Rheumatology, Department of Medicine, Toronto Western Hospital, Mount Sinai Hospital; Institute of Health Policy, Management and Evaluation,

University of Toronto, Toronto, Ontario, Canada

Correspondence to Professor Martin Aringer, Internal Medicine III, Medical Faculty, Technical University of Dresden, Dresden, Germany;

martin.aringer@uniklinikum-dresden.de

Contributors The response has been drafted together by all four authors. All have approved the final version.

Funding The authors have not declared a specific grant for this research from any funding agency in the public, commercial or not-for-profit sectors.

Competing interests None declared.

Patient consent for publication Not required.

Provenance and peer review Commissioned; internally peer reviewed.

(C) Author(s) (or their employer(s)) 2019. No commercial re-use. See rights and permissions. Published by BMJ.

\section{Check for updates}

To cite Aringer M, Costenbader K, Dörner T, et al. Ann Rheum Dis Epub ahead of print: [please include Day Month Year]. doi:10.1136/annrheumdis-2019-216803

Received 10 December 2019

Accepted 12 December 2019

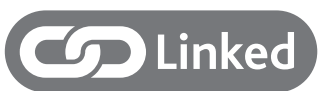

http://dx.doi.org/10.1136/annrheumdis-2019-216712

Ann Rheum Dis 2019;0:1. doi:10.1136/annrheumdis-2019-216803

\section{ORCID iDs}

Martin Aringer http://orcid.org/0000-0003-4471-8375

Thomas Dörner http://orcid.org/0000-0002-6478-7725

\section{REFERENCES}

1 Sacre K, Delaval L, Dossier A, et al. New 2019 SLE EULAR/ACR classification criteria are valid for identifying patients with SLE among patients admitted for pericardial effusion. Ann Rheum Dis 2019:annrheumdis-2019-216712.

2 Aringer M, Costenbader K, Daikh D, et al. 2019 European League against Rheumatism/ American College of rheumatology classification criteria for systemic lupus erythematosus. Ann Rheum Dis 2019;78:1151-9.

3 Aringer M, Costenbader K, Daikh D, et al. 2019 European League against Rheumatism/ American College of rheumatology classification criteria for systemic lupus erythematosus. Arthritis Rheumatol 2019;71:1400-12.

4 Tedeschi SK, Johnson SR, Boumpas D, et al. Developing and refining new candidate criteria for systemic lupus erythematosus classification: an international collaboration. Arthritis Care Res 2018;70:571-81. 